

Received 5th December 2016

DOI: $10.1039 / c 6 r a 27795 k$

rsc.li/rsc-advances
Cite this: RSC Adv., 2017, 7, 13798 Accepted 23rd February 2017

\section{Biobased copolyesters: synthesis, crystallization behavior, thermal and mechanical properties of poly(ethylene glycol sebacate-co-ethylene glycol 2,5-furan dicarboxylate)}

\begin{abstract}
Guoqiang Wang, Min Jiang, Qiang Zhang, Rui Wang and Guangyuan Zhou*
A series of biobased copolyesters, poly(ethylene sebacate-co-ethylene 2,5-furandicarboxylate) (PESF), were synthesized from available biobased ethylene glycol (EG), sebacic acid (SA) and 2,5furandicarboxylic acid (FDCA) through a two-step melt polycondensation method. The composition, molecular weight and its distribution, crystal structure, and crystallization behavior of PESFs were investigated by ${ }^{1} \mathrm{H}$ NMR, GPC, WAXD, and DSC methods, respectively. Tensile properties were also evaluated. While increasing the content of the FDCA unit, the glass transition temperatures of PESFs increased and the crystallization rates of PESFs decreased. Compared with poly(ethylene sebacate) (PES), PESF20 showed two melting peaks due to the formation of secondary crystals (small and imperfects crystals) caused by the incorporation of FDCA during the isothermal crystallization process. POM data showed that the nucleation density of PESF10 and PESF20 increased and the size of spherulites decreased due to the chain irregularity caused by randomization distribution with the introduction of FDCA. However, the crystal structure remained unchanged. Ring-banded spherulites were not detected for PESF20 in a wide temperature range $\left(28-44^{\circ} \mathrm{C}\right)$ as the incorporation of FDCA can restrict lamellar twisting and scrolling of PES segments. The thermal transition and mechanical properties of copolymers are tunable with the composition.
\end{abstract}

\section{Introduction}

Recently, biobased polymers have become an effective substitute for fossil-based polymers, which have gained more attention due to the inevitable depletion of fossil resources and environmental pollution. ${ }^{\mathbf{1 - 4}}$ A particularly attractive class of biobased polymers are aliphatic polyesters. Aliphatic polyesters such as polyhydroxyalkanoates (PHA), polylactic acid (PLA), poly(butylene succinate) (PBS) and polycaprolactone (PCL) attract considerable attention due to their biodegradability and biobased origin. There are many biobased diacid and diol monomers, such as succinic acid, 1,3-propanediol, 1,4-butanediol (BDO), and lactic acid. ${ }^{5-8}$ Among them, sebacic acid (SA), a naturally occurring dicarboxylic acid, is an intermediate product of u-oxidization of long chain aliphatic acids. ${ }^{9}$ Compared with short chain diacids, sebacic acid is more suitable for the preparation of polyesters due to a long - $\left(\mathrm{CH}_{2}\right)_{-}$ sequence and can prevent intra-molecular cyclization. Moreover, SA has a long enough series of $-\mathrm{CH}_{2}-$ groups, which can improve the liquidity and crystal quality of polyester. Ethylene glycol (EG) drived from the product of cracking of sorbitol is

Changchun Institute of Applied Chemistry, Chinese Academy of Science, Changchun 130022, China.E-mail: gyzhou@ciac.ac.cn also a biobased monomer. Compared with BDO, EG is more suitable for the preparation of polyesters and can prevent intramolecular cyclization.

Although biobased poly(ethylene sebacate) (PES) derived from sebacic acid and ethylene glycol has been synthesized, ${ }^{\mathbf{1 0 , 1 1}}$ the thermal properties, durability, and mechanical properties of PES are unsatisfactory in some applications like other aliphatic polyesters. An efficient strategy to improve the performance of aliphatic polyesters is to introduce some rigid molecular structure into the polymeric backbone. Recently, isosorbide has gained more attention due to two cis-fused tetrahydrofuran rings. However, the hydroxyl group in endo position is easier to form intra-molecular hydrogen bond with the oxygen in the other ring, which leads to the poor reactivity of the secondary hydroxyl group and the low number average molecular weights of copolyesters $\left(<18000 \mathrm{~g} \mathrm{~mol}^{-1}\right){ }^{9}$ 2,5-Furandicarboxylic acid (FDCA) is another important biological monomer with furan ring, which can be produced from cellulose. ${ }^{12-14}$ Previous approaches to synthesizing FDCA use dehydration processes to convert hexose sugars into hydroxymethyl furfural (HMF), which is then oxidized to form FDCA. However, it is not the most desired route due to the expensive purification procedures for synthesizing HMF. Recently, since 2 -furoic acid can readily be made from lignocellulose ${ }^{15}$ Banerjee provides a new way to 
transform inedible biomass and $\mathrm{CO}_{2}$ into FDCA. ${ }^{16}$ FDCA has been highlighted as biobased replacement of fossil-based terephthalic acid (TPA). ${ }^{17-22}$ Therefore, FDCA is an ideal candidate satisfied the above-mentioned issues.

In our previous report, lots of FDCA-based polyesters have been prepared, involving poly(ethylene 2,5-furandicarboxylate), poly(trimethylene 2,5-furandicarboxylate), poly(butylene 2,5furandicarboxylate), poly(hexylene 2,5-furandicarboxylate), and poly(octylene 2,5-furandicarboxylate). ${ }^{20}$ In the present paper, in order to improve the thermal and mechanical properties of PES, we further synthesized a series of new biobased copolyesters poly(ethylene sebacate-co-ethylene 2,5-furandicarboxylate) (PESFs). The effects of FDCA on the microstructure, thermal and mechanical properties of copolyesters were emphasized. Additionally, since the physical properties of polymers greatly depend on the spherulite morphology, crystal structure and degree of crystallinity, the crystallization behavior of copolyesters were also investigated. It was found that their properties varied from thermoplastics to elastomers with the copolymer composition. It is expected that the results will be of great help to understanding the relationships between structures and properties in the case of aliphatic-aromatic copolyesters with incorporated FDCA.

\section{Experimental}

\subsection{Materials}

Sebacic acid (SA, 99\%) and tetrabutyl titanate (99\%), were purchased from Tianjin Guangfu Fine Chemical Research Institute. Ethylene glycol (EG, 99\%), was purchased from Beijing Chemical Works. 2,5-Furandicarboxylic acid (FDCA, 99.5\%), was purchased from Chinese University of Science and Technology. All other regents were used as received.

\subsection{Synthesis of copolyesters}

PESFs were synthesized by a two-step esterification and polycondensation process, as depicted in Scheme 1. The molar ratio of EG : (SA + FDCA) was 1.6:1 and appropriate amount of

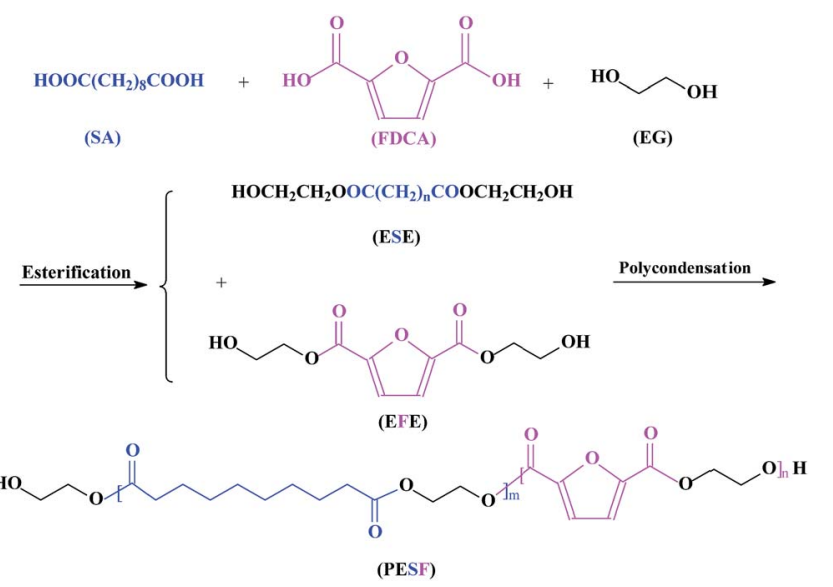

Scheme 1 Synthesis of PESFs copolyesters from EG, SA and FDCA via two-step esterification-polycondensation procedure. tetrabutyl titanate was used as a catalyst. During the first stage (esterification process), the mixture was heated at $190{ }^{\circ} \mathrm{C}$ under a nitrogen atmosphere for $1 \mathrm{~h}$, at $210^{\circ} \mathrm{C}$ for additional 1-3 h. In the polycondensation step, the pressure was reduced to $100 \mathrm{~Pa}$ and the temperature was raised up to $230{ }^{\circ} \mathrm{C}$ to completely remove the byproduct and the unreacted monomers, and the polycondensation was continued for $5 \mathrm{~h}$. Poly(ethylene sebacate) (PES) and poly(ethylene 2,5-furandicarboxylate) (PEF) were also prepared by a similar synthetic procedure for comparison. The samples with various feed ratios are displayed in Table 1.

\subsection{Characterization}

Weight-average molecular weight $\left(M_{\mathrm{w}}\right)$, number-average molecular weight $\left(M_{\mathrm{n}}\right)$, and their distribution (PDI) were obtained by Waters gel permeation chromatography (GPC). 1,1,1,3,3,3-Hexafluoro-2-propanol (HFIP) was used as solvent and polystyrene standards were used for calibration.

FT-IR spectra were recorded in the range $4000-400 \mathrm{~cm}^{-1}$ with a Bruker IFS $66 \mathrm{~V}$ in $\mathrm{KBr}$ and polyethylene medium.

${ }^{1} \mathrm{H}$ NMR spectra were recorded on a Bruker Avance $600 \mathrm{MHz}$ apparatus, using trifluoroacetic acid-d $\left(\mathrm{CF}_{3} \mathrm{COOD}\right)$ as solvent for all samples.

Thermogravimetric analysis (TGA) of PESFs was performed by the Mettler Instrument from 30 to $600{ }^{\circ} \mathrm{C}$ at a heating rate of $10{ }^{\circ} \mathrm{C} \mathrm{min}^{-1}$ under a air flow.

Differential scanning calorimetry (DSC) measurements were carried out with a Mettler Instrument under a nitrogen flow. The samples were heated for the first run from -50 to $250{ }^{\circ} \mathrm{C}$, at $250{ }^{\circ} \mathrm{C}$ for $5 \mathrm{~min}$ to erase the thermal history, then cooled to $-50{ }^{\circ} \mathrm{C}$ at a rate of $10^{\circ} \mathrm{C} \mathrm{min}^{-1}$, and heated again for the second run from -50 to $250{ }^{\circ} \mathrm{C}$ at a rate of $10^{\circ} \mathrm{C} \mathrm{min}{ }^{-1}$. For the investigation of isothermal crystallization kinetics, the samples were initially melted at $100{ }^{\circ} \mathrm{C}$ for $5 \mathrm{~min}$, then quenched to the desired crystallization temperature at a rate of $60{ }^{\circ} \mathrm{C} \mathrm{min}^{-1}$. After the completion of isothermal crystallization, the samples were directly heated to the melt at a rate of $10{ }^{\circ} \mathrm{C} \mathrm{min}{ }^{-1}$. The heat flows during both crystallization and melting processes were recorded for the later kinetics analysis of isothermal crystallization and the estimation of the equilibrium melting point.

Wide-angle X-ray diffraction (WAXD) patterns were recorded on a Bruker $\mathrm{D} 8$ focus, using $\mathrm{Cu}-\mathrm{K}_{\alpha}$ radiation in the scan ranged from $5^{\circ}$ to $45^{\circ}(\lambda=0.154 \mathrm{~nm})$.

Spherulite morphologies of the copolyesters were observed by a Leica DM 2500P polarized optical microscope (POM) equipped with a Linkam LTS350 hot stage. The samples were placed between two cover glasses, melted and pressed at $100{ }^{\circ} \mathrm{C}$ for $5 \mathrm{~min}$, then quenched to predetermined temperature $\left(T_{\mathrm{c}}\right)$ for isothermal crystallization, and the representative spherulitic morphologies were recorded.

Tensile tests were done with Instron-1121 tester at $25{ }^{\circ} \mathrm{C}$ in accordance with ASTM D638. The crosshead speed was $5 \mathrm{~mm}$ $\min ^{-1}$. The dumbbell-shaped samples of $4 \mathrm{~mm}$ width, and 2 $\mathrm{mm}$ thickness were made by a HAAKE MiniJet Injection moulding machine. At least three specimens were tested for each sample. The Young's modulus, tensile strength and elongation at break were obtained. 
Table 1 Molecular characteristics of PES, PEF and PESFs

\begin{tabular}{|c|c|c|c|c|c|c|c|c|}
\hline \multirow[b]{2}{*}{ Sample } & \multirow{2}{*}{$\begin{array}{l}\Phi_{\mathrm{EF}} \text { in feed } \\
(\mathrm{mol} \%)\end{array}$} & \multirow{2}{*}{$\begin{array}{l}{ }^{1} \mathrm{H} \text { NMR } \\
\begin{array}{l}\Phi_{\mathrm{EF}} \text { in copolymer } \\
(\mathrm{mol} \%)\end{array}\end{array}$} & \multicolumn{3}{|c|}{${ }^{1} \mathrm{H}$ NMR } & \multirow[b]{2}{*}{$M_{\mathrm{n}}\left(\mathrm{g} \mathrm{mol}^{-1}\right)$} & \multirow[b]{2}{*}{$M_{\mathrm{w}}\left(\mathrm{g} \mathrm{mol}^{-1}\right)$} & \multirow[b]{2}{*}{ PDI } \\
\hline & & & $L_{\mathrm{n}, \mathrm{ES}}$ & $L_{\mathrm{n}, \mathrm{EF}}$ & $R$ & & & \\
\hline PES & 0 & 0 & - & - & - & 48200 & 96000 & 2.00 \\
\hline PESF10 & 10 & 11.2 & 10.5 & 1.1 & 1.00 & 56200 & 113000 & 2.02 \\
\hline PESF20 & 20 & 15.7 & 5.1 & 1.1 & 1.11 & 54400 & 147000 & 2.70 \\
\hline PESF50 & 50 & 54.4 & 2.0 & 1.9 & 1.03 & 138000 & 328000 & 2.36 \\
\hline PESF60 & 60 & 62.8 & 1.7 & 2.3 & 1.04 & 53000 & 115000 & 2.16 \\
\hline PESF70 & 70 & 71.3 & 1.4 & 3.1 & 1.03 & 123000 & 300000 & 2.44 \\
\hline PESF80 & 80 & 83.0 & 1.2 & 3.3 & 1.11 & 81000 & 197000 & 2.43 \\
\hline PESF90 & 90 & 91.5 & 1.1 & 8.0 & 1.01 & 64600 & 146000 & 2.26 \\
\hline PEF & 100 & 100 & - & - & - & 103000 & 252000 & 2.44 \\
\hline
\end{tabular}

\section{Results and discussion}

\subsection{Synthesis and characterization of copolyesters}

Biobased copolyesters PESFs were synthesized by a traditional two-step melt esterification and polycondensation process, as shown in Scheme 1. The molecular characteristics obtained by GPC are summarized in Table 1. The number average molecular weight $\left(M_{\mathrm{n}}\right)$ ranges from 28100 to $138000 \mathrm{~g} \mathrm{~mol}^{-1}$ and polydispersity ranged from 1.9 to 2.7 .

The chemical structure and composition of PESFs were determined by FTIR and ${ }^{1} \mathrm{H}$ NMR. Fig. 1 shows the FTIR spectra of PES, PEF and PESFs. The strong absorption at $1735 \mathrm{~cm}^{-1}$ is attributed to the ester bonds $\left(\nu_{\mathrm{C}=\mathrm{O}}\right)$. In comparison with PES, some extra absorption peaks appear for PESFs due to the introduction of FDCA, including $\nu_{\mathrm{C}-\mathrm{H}}$ of the furan ring at 3128 $\mathrm{cm}^{-1}$, furan $\mathrm{C}=\mathrm{C}$ bond at $1585 \mathrm{~cm}^{-1}$ and $1520 \mathrm{~cm}^{-1} .^{23}$ They increase with increasing the molar percentage of $\mathrm{EF}\left(\Phi_{\mathrm{EF}}\right)$.

As ${ }^{1} \mathrm{H}$ NMR is sensitive to the monomer sequence, it is used to analyze the sequential structures of PESFs. Fig. 2 shows the

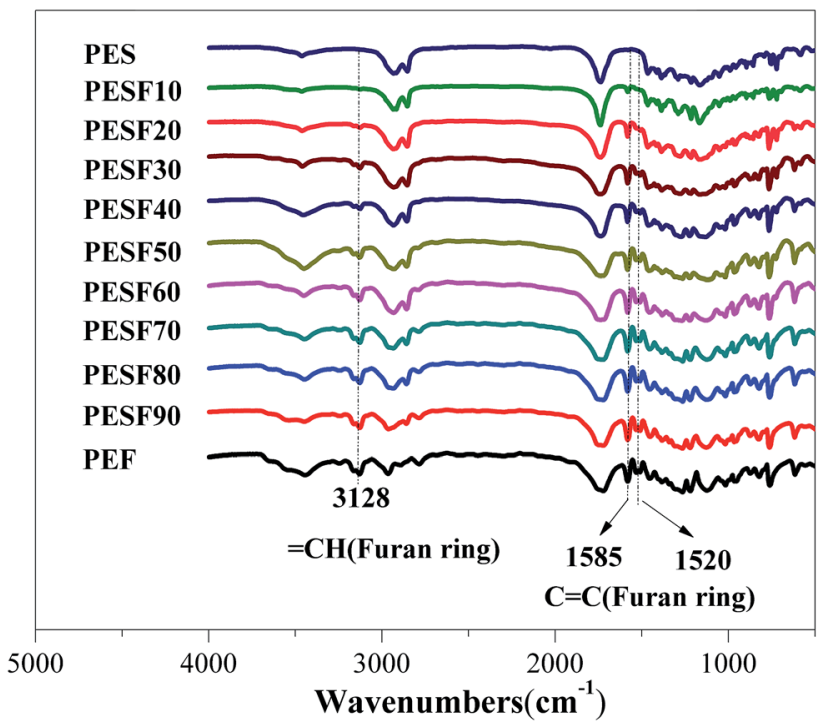

Fig. 1 FT-IR spectra of the PES, PEF and PESFs.
${ }^{1} \mathrm{H}$ NMR spectra of PES, PEF and PESFs. The attributions of the chemical shifts are shown in Scheme 2 and Fig. 2. For PES, the chemical shifts of $\mathrm{CH}_{2}$ in EG appear at $4.66 \mathrm{ppm}\left(\mathrm{a}_{1}\right)$, and for $\mathrm{PEF}$, the chemical shifts of $\mathrm{CH}_{2}$ in EG appear at $5.08 \mathrm{ppm}\left(\mathrm{a}_{4}\right)$. For PESFs, some new chemical shifts of $\mathrm{CH}_{2}$ in the EG unit appear at 4.78 and $4.90 \mathrm{ppm}\left(\mathrm{a}_{2}\right.$ and $\left.\mathrm{a}_{3}\right)$. Therefore, these proton signals were applied to analyze the comonomer composition and the sequential structures of PESFs.

The integrated proton resonance intensities for the signal (2,5-furandicarboxylate unit, F) was employed to quantitatively determine the comonomer compositions of ethylene 2,5-furandicarboxylate $\left(\Phi_{\mathrm{EF}}\right)$ according to eqn (1). As shown in Table 1, it is found that the molar percentage of EF $\left(\Phi_{\mathrm{EF}}\right)$ in PESFs is consistent with that in the monomer feed. The number-average sequence length of ES and EF repeating units $\left(L_{\mathrm{n}, \mathrm{ES}}\right.$ and $\left.L_{\mathrm{n}, \mathrm{EF}}\right)$ and the degree of randomness $(R)$ were calculated respectively according to eqn (2)-(4). With increasing the molar percentage of $\mathrm{EF}\left(\Phi_{\mathrm{EF}}\right)$, the $L_{\mathrm{n}, \mathrm{EF}}$ increases and $L_{\mathrm{n}, \mathrm{ES}}$ decreases. For all PESFs, the degree of randomness are very close to 1.0 , which indicates that PESFs are random copolymers.



Fig. $2{ }^{1} \mathrm{H}$ NMR spectra of PES, PEF and PESFs. 
SES

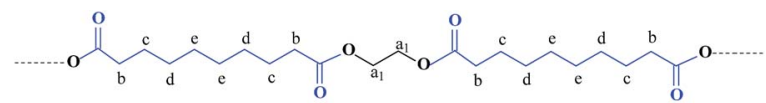

SEF

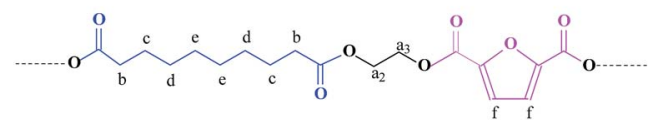

FEF

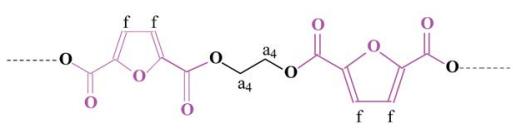

Scheme 2 Chemical structures of SES, SEF and FEF unites in PESFs.

$$
\begin{gathered}
\Phi_{\mathrm{EF}}\left(\mathrm{mol}^{\circ}\right)=2 I_{\mathrm{f}} /\left(2 I_{\mathrm{f}}+I_{\mathrm{c}}\right) \times 100 \% \\
L_{\mathrm{n}, \mathrm{ES}}=1+2 I_{\mathrm{a}_{1}} /\left(I_{\mathrm{a}_{2}}+I_{\mathrm{a}_{3}}\right) \\
L_{\mathrm{n}, \mathrm{EF}}=1+2 I_{\mathrm{a}_{4}} /\left(I_{\mathrm{a}_{2}}+I_{\mathrm{a}_{3}}\right) \\
R=1 / L_{\mathrm{n}, \mathrm{ES}}+1 / L_{\mathrm{n}, \mathrm{EF}}
\end{gathered}
$$

\subsection{Thermal stability}

Fig. 3 shows TGA (a) and DTG (b) curves of PES, PEF, and PESFs under dynamic air atmosphere. The thermal properties data are summarized in Table 2. The decomposition temperature at 5\% weight loss $\left(T_{\mathrm{d}, 5 \%}\right)$ of copolyesters are in a range between $347^{\circ} \mathrm{C}$ and $376{ }^{\circ} \mathrm{C}$, and the weight of residues at $600{ }^{\circ} \mathrm{C}$ is in the range of $3.0-11.0 \%$. PES is almost completely degraded, while $11.0 \%$ is left for PEF. Compared with PES, $T_{\mathrm{d}, 5 \%}$ of PEF is higher and the weight loss is lower. These results show PEF has better thermal stability than PES. For all copolymers, the $T_{\mathrm{d}, 5 \%}$ and the weight of residues at $600{ }^{\circ} \mathrm{C}$ are irregular, but weight loss does not take place before $300{ }^{\circ} \mathrm{C}$, which indicates that they exhibit excellent thermal stability. According to the report, the thermal stability of a polymer is determined by the bond energy between atoms in the main chain. ${ }^{24}$ Structures of PESFs are similar to that of poly(butylene succinate-co-terephthalate) (PBST), the chemical bonds in the main chain are strong bonds, and therefore PESFs also exhibit excellent thermal stability.

\subsection{Non-isothermal and isothermal crystallization behavior}

As is known, the crystallization has a great influence on mechanical properties. Fig. 4 shows the non-isothermal crystallization behavior of PES, PEF, and PESFs.

The composition of PESFs has little influence on the thermal stability but plays a great influence on the crystallization and melting behavior. From Fig. $4 \mathrm{a}$, it can be seen that the crystallization exotherms of PESFs ( $\Phi_{\mathrm{EF}} \leqq 20 \%$ ) become more and more wide, the crystallization peak temperature $\left(T_{\mathrm{c}}\right)$ shifts to a lower temperature and the corresponding $\Delta H_{\mathrm{c}}$ decreases with increasing the FDCA content, which indicates that the crystallization becomes difficult and imperfect crystals appear with increasing the FDCA content. Meanwhile, melting enthalpy $\left(\Delta H_{\mathrm{m}}\right)$ in the first heating run is higher than that obtained from the second heating run, which may be explained by the fact that specimens are obtained under a natural cooling mode and therefore the crystallization time is longer. Although PESF30 and PESF40 all neither crystallize nor melt during the cooling and second heating at $10{ }^{\circ} \mathrm{C}$ $\min ^{-1}$, melting peaks appear at $40{ }^{\circ} \mathrm{C}\left(\Delta H_{\mathrm{m}}=28.0 \mathrm{~J} \mathrm{~g}^{-1}\right)$, and $39{ }^{\circ} \mathrm{C}\left(\Delta H_{\mathrm{m}}=25.7 \mathrm{~J} \mathrm{~g}^{-1}\right)$, respectively, during the first heating at $10{ }^{\circ} \mathrm{C} \mathrm{min}{ }^{-1}$. The results are clearly indicative of the fact that they can crystallize slowly by natural cooling. Thus, PESF30 and PESF40 are rubbery polymers, with a $T_{\mathrm{g}}$ below room temperature and low crystallinity. In contrast, PESF60-90 all neither crystallize nor melt during the first heating, cooling, and second heating at $10{ }^{\circ} \mathrm{C} \mathrm{min}^{-1}$, which shows that they


Fig. 3 TGA (a) and DTG (b) curves of PES, PEF, and PESFs under dynamic air atmosphere. 
Table 2 Thermal properties data of PES, PEF and PESFs (scanning rate: $10{ }^{\circ} \mathrm{C} \mathrm{min}^{-1}$ )

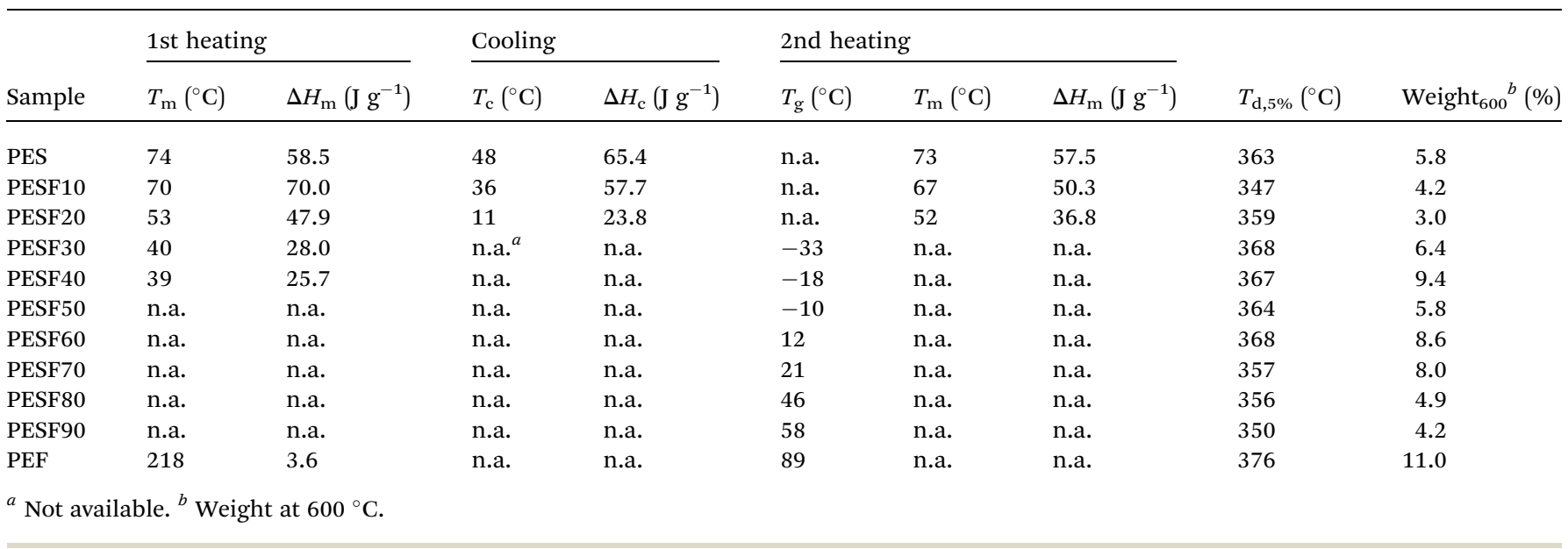
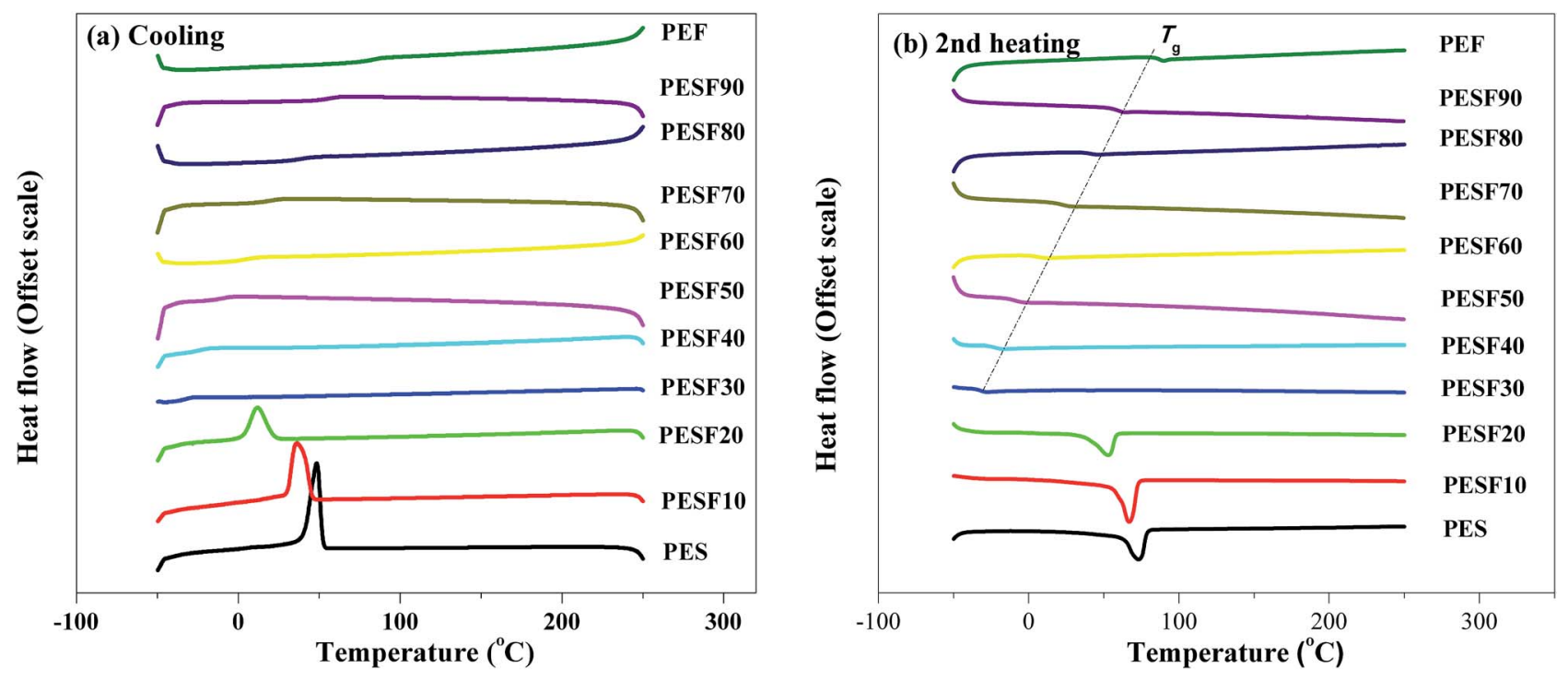

Fig. 4 DSC recorded at $10 \mathrm{~K} \mathrm{~min}^{-1}$ (a) cooling and (b) 2nd heating curves of PES, PEF and PESFs.

have no crystallizability and they are amorphous as the introduction of FDCA breaks the regularity of the molecular chain. In addition, like PESF30 and PESF40, PEF can only crystallize slowly by natural cooling, with low melting enthalpy $\left(\Delta H_{\mathrm{m}}\right)$ of $3.6 \mathrm{~J} \mathrm{~g}^{-1}$ during the first heating, which can be attributed to the high molecular weight and an angle of $129.4^{\circ}$ between carboxylic acid carbons. The results agrees well with that reported by Koros. ${ }^{17}$ According to the report by Koros, the nonlinear character in FDCA combined with the permanent dipole frustrates the crystallization process, resulting in the slow crystallization rate of PEF.

During the second heating, the mobility of molecule chains decreases due to the introduction of furan ring, which leads to the enhancement of glass transition temperature $\left(T_{\mathrm{g}}\right)$. Unfortunately, no remarkable glass transition is detected for PES, PESF10 and PESF20 due to the limitation of our instrument.

Only isothermal crystallization kinetics of PES, PESF10 and PESF20 investigated by differential scanning calorimetry at different temperatures are shown in Fig. 5 because the crystallizability of other copolymers is weak.

For the sake of the completion of crystallization within an approximate crystallization time, the intervals of crystallization temperature of PESF20 gradually shift to lower temperature ranges than that of PES, which means the crystallization rate of PESFs reduce due to the incorporation of FDCA. Evidently, with increasing the content of FDCA unit, furan ring restricts the chain mobility and depresses the polymer crystallization. Moreover, with increasing the isothermal crystallization temperature $\left(T_{\mathrm{c}}\right)$, the exothermic peak becomes broader and the crystallization time becomes longer due to the decline of the crystallization rate.

In order to understand the isothermal crystallization process, we use the well-known Avrami model. ${ }^{25,26}$ A comparative study of the crystallization kinetics of neat PES and PESF20 is carried out. The relative crystallinity $\left(X_{t}\right)$ can be defined as follow: 

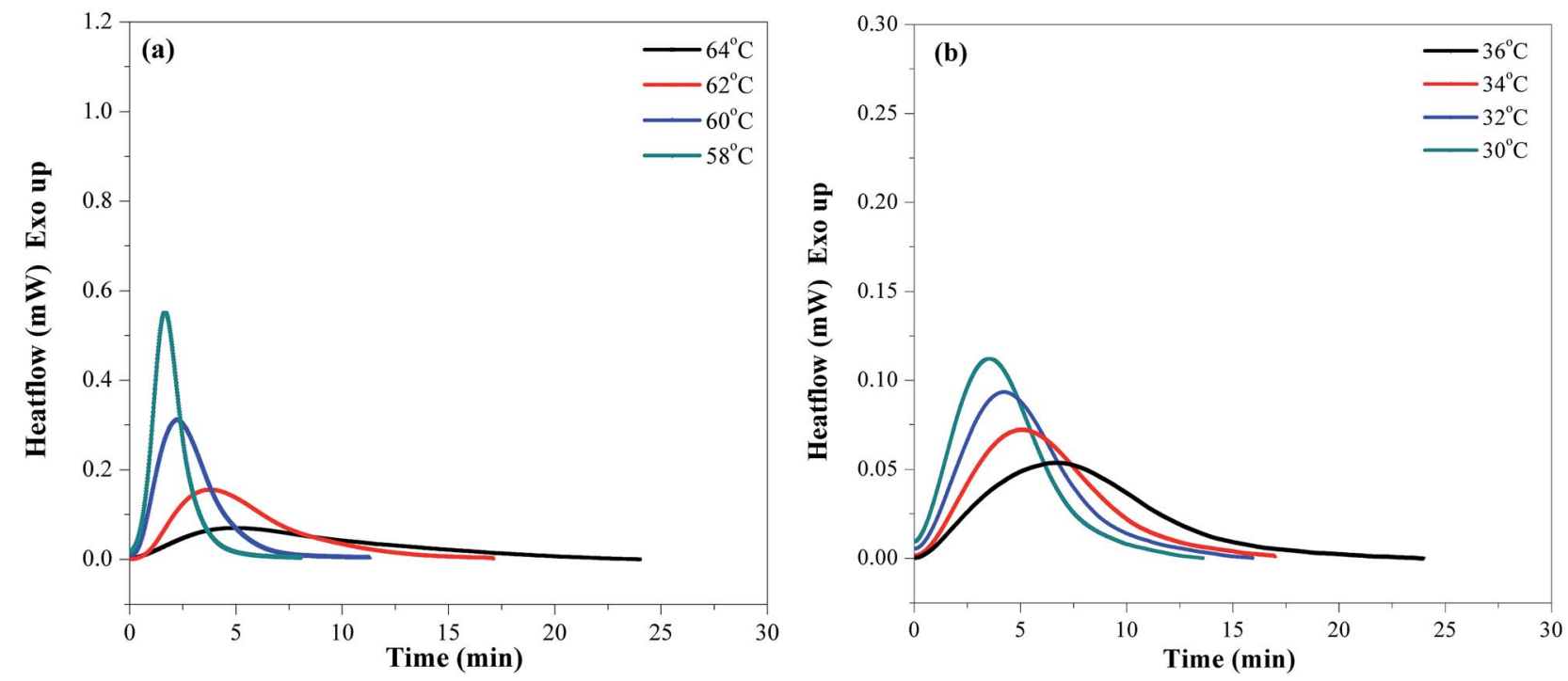

Fig. 5 DSC thermograms of isothermal crystallization at different temperatures: (a) PES, (b) PESF20.

$$
X_{t}=\frac{X_{t}(t)}{X_{t}(\infty)}=\frac{\int_{0}^{t}\left(\mathrm{~d} H_{\mathrm{c}} / \mathrm{d} t\right) \mathrm{d} t}{\int_{0}^{\infty}\left(\mathrm{d} H_{\mathrm{c}} / \mathrm{d} t\right) \mathrm{d} t}
$$

where $\mathrm{d} H_{\mathrm{c}} / \mathrm{d} t$ denotes the rate of heat flow, $X_{t}(t)$ and $X_{t}(\infty)$ represent the absolute crystallinity at the elapsed time during the course of crystallization and at the end of the crystallization process, respectively.

Fig. 6 shows the relative degree of crystallinity with time for isothermal crystallization at different temperatures of PES and PESF20. Fig. 6 shows the similar S-shaped curves, which are consistent with Avrami equation. The crystallization rate is usually defined as the inverse of the crystallization halftime $\left(t_{1 / 2}\right)$. The $t_{1 / 2}$ values for PES, PESF10 and PESF20 are summarized in Table 3 . With increasing the crystallization temperature, $t_{1 / 2}$ increases due to the decreasing of the crystallization rate, which is consistent with the results in Fig. 5.

Avrami model is frequently used as a common method to obtain relevant parameters characterizing the crystallization kinetics. ${ }^{27,28}$

Just as the Avrami model depicted, the relative degree of crystallinity is a function of time, then the Avrami equation can be defined as follow:

$$
X_{t}=1-\exp \left(-k t^{n}\right)
$$

where $n$ is the Avrami exponent depending on the mechanism of nucleation and the growth geometry of crystals, and $k$ is a rate constant on crystallization, which is related to nucleation and crystal growth. The Avrami equation can be modified as:


Fig. 6 Relative degree of crystallinity with time for isothermal crystallization at different temperatures: (a) PES, (b) PESF20. 
Table 3 Avrami analysis for isothermal crystallization of PES, PESF10 and PESF20

\begin{tabular}{llclll}
\hline Sample & $T_{\mathrm{c}}\left({ }^{\circ} \mathrm{C}\right)$ & $t_{1 / 2}(\mathrm{~min})$ & $k\left(\mathrm{~min}^{-n}\right)$ & $n$ & $n$ (average) \\
\hline \multirow{2}{*}{ PES } & 58 & 1.85 & 0.194 & 2.08 & 1.87 \\
& 60 & 2.67 & 0.102 & 1.95 & - \\
& 62 & 4.93 & 0.041 & 1.77 & - \\
& 64 & 7.40 & 0.025 & 1.66 & - \\
PESF10 & 54 & 1.76 & 0.153 & 2.16 & 2.07 \\
& 56 & 3.46 & 0.045 & 2.14 & - \\
& 58 & 6.25 & 0.018 & 1.94 & - \\
PESF20 & 30 & 13.0 & 0.004 & 2.04 & - \\
& 30 & 4.80 & 0.023 & 2.16 & 2.16 \\
& 34 & 5.77 & 0.014 & 2.22 & - \\
& 36 & 7.42 & 0.009 & 2.15 & - \\
& & 9.20 & 0.007 & 2.09 & - \\
\end{tabular}

$$
\ln \left(-\ln \left(1-X_{t}\right)\right)=\ln k+n \ln t
$$

From the slope and the intercept of the Avrami plots, the parameters $k$ and $n$, respectively, are estimated and summarized in Table 3. The average value of $n$ for PES was 1.87 , which indicates that both one-dimensional and two-dimensional crystal growths simultaneously occur. The average value of $n$ for PESF20 is 2.16, which indicates that both two-dimensional and three-dimensional crystal growths simultaneously occur. With decreasing the supercooling (difference between $T_{\mathrm{m}}^{0}$ and $T_{\mathrm{c}}$ ), the values of $k$ obviously decrease. The $k$ values of PES and PESF 10 at 58 and $60^{\circ} \mathrm{C}$ are compared. It is found that the $k$ value decreases with increasing the content of FDCA unit, which means that the crystallization rate decreases. Because of the incorporation of the FDCA units into the PES chains, the FDCA units along the polymer chain are hard to mobile and easy to form nucleuses. The variation of $n$ from 1.87 to 2.16 also indicates that the mechanism of the manner of crystal growth of the copolyesters have been gradually altered from both one- and two-dimensional crystal growths to two- and three-dimensional crystal growths.

Fig. 7 shows the melting curves of PES and PESF20 after isothermal crystallization at the indicated temperatures. Compared with the single melting peak of PES, that of PESF20 shows two melting peaks due to the introduction of FDCA. Peak $\mathrm{I}$ in Fig. 7b has a low amplitude and its temperature position linearly increases with increasing crystallization temperature. However, its area remains almost constant and its temperature position is still about $5{ }^{\circ} \mathrm{C}$ higher than $T_{\mathrm{c}}$, which is the typical characteristic of an "annealing peak". As proposed by Wei et al., by analogy with poly(propylene sebacate), peak I can be attributed to the melting of secondary crystals (small and imperfects crystals) formed during the isothermal crystallization process. ${ }^{29}$ The same observations were reported in the case of poly(ethylene-2,5-furanoate) and poly(ethylene terephthalate). ${ }^{30,31}$

Fig. 8 shows the Hoffman-Weeks plots for PES, PESF10, and PESF20. The values of the equilibrium melting point for PES, PESF10, and PESF20 were determined to be 89.4, 71.4, and $60.5{ }^{\circ} \mathrm{C}$, respectively. That's to say, the molecular mobility is confined due to the introduction of rigid segments (FDCA) into PES, and hence the crystallization ability declines. This behavior had also been observed by Wei et al. in isosorbidepoly(decamethylene sebacate) and isosorbide-poly(propylene sebacate) systems. ${ }^{9,29}$

\subsection{Crystal structure and spherulitic morphology}

In order to study the relationship between the composition and crystallizability of PESFs, the crystal structures of PESFs were further performed with WAXD. As shown in Fig. 9, PES shows two diffraction peaks with relatively strong intensities at 21.9 and $24.6^{\circ}$. With the introduction of FDCA, PESF50 was a amorphous copolymer due to the randomization distribution and the incompatibility in crystal lattices of ES and EF. PESF10 and
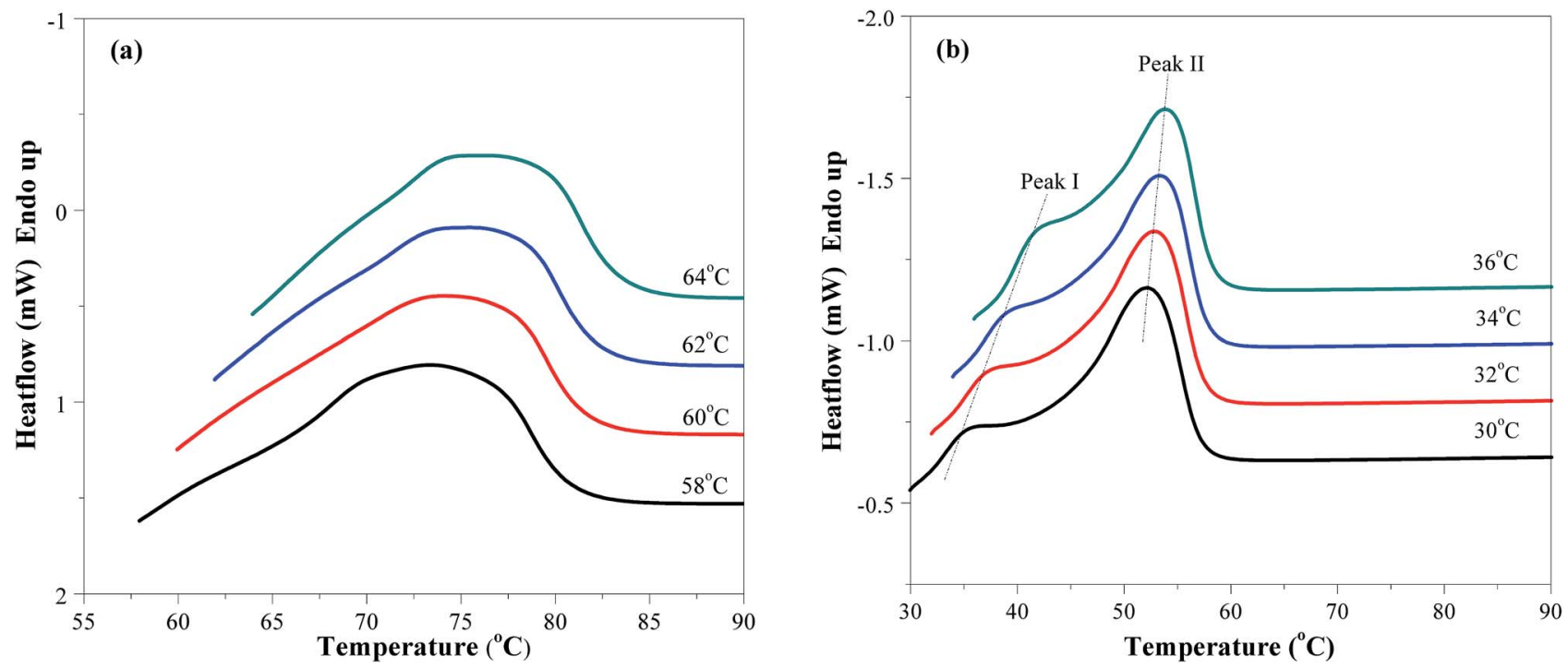

Fig. 7 Melting behavior of (a) PES and (b) PESF20 after isothermal crystallization at different temperatures. 


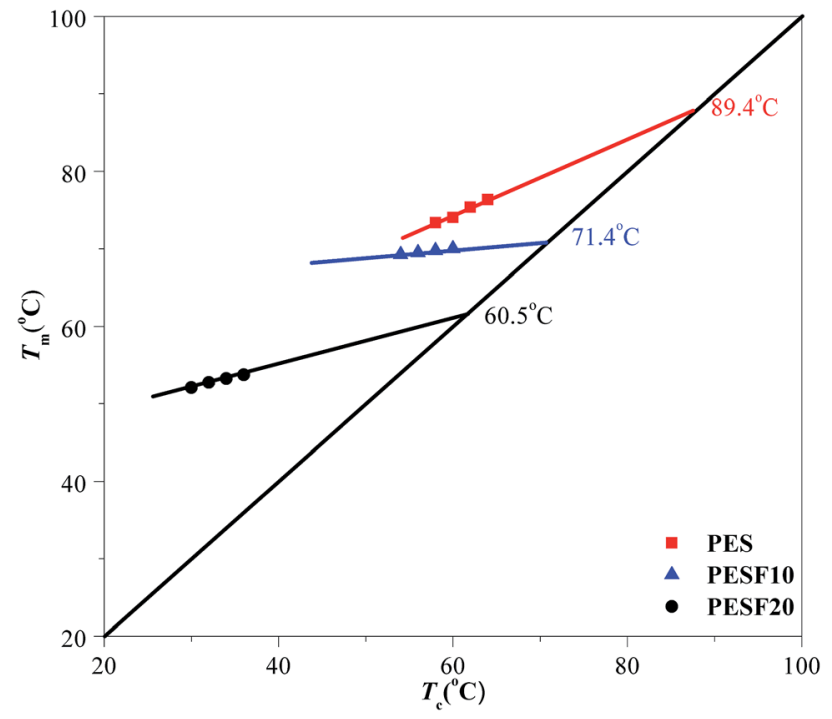

Fig. 8 Hoffman-Weeks plots of PES, PESF10 and PESF2O.



Fig. 9 WAXD patterns of PES, PESF10 and PESF20.

PESF20 were found to show two diffraction peaks at 21.9 and $24.6^{\circ}$. No new peak is observed for PESF10 and PESF20. WAXD patterns of PESF10 and PESF20 are the same as that of PES, indicating that they have the same crystal structure as PES. It also indicates that the EF segment is excluded from crystal region of PES and subject to present as an amorphous region due to its bulky furan ring. The variation of the degree of crystallinity $\left(X_{\mathrm{c}}\right)$ observed in the WAXD pattern is in agreement with the changes of the fusion enthalpy.

It is well known that the physical properties largely depend on the spherulitic morphology. ${ }^{32}$ The effects of copolymer composition and crystallization temperature on the spherulitic morphologies of PES, PESF10 and PESF20 were further investigated by POM. Fig. 10 displays a series of POM images of PES, PESF10 and PESF20 isothermally crystallized at various temperatures. With the introduction of FDCA, PESF10 and
PESF20 form large numbers of nuclei even at elevated temperatures. Compared with PES and PESF10, PESF20 gives slightly smaller spherulites due to higher nucleation density.

Moreover, with increasing crystallization temperature, the nucleation density of PES decreases and the size of spherulites increases due to the difficulty of nucleation at high crystallization temperature. Unfortunately, it is difficult to observe the variation of the size of spherulites for PESF10 and PESF20 as many crystal nuclei are formed and the crystals collide with each other quickly.

In general, ring-banded spherulites are commonly observed in short chain aliphatic polyesters. ${ }^{33}$ As expected, besides Maltese cross spherulites, ring-banded spherulites were also observed for PES at 62 and $66{ }^{\circ} \mathrm{C}$, which is consistent with the results of Keith. ${ }^{10}$ Ring-banded spherulites couldn't be detected for PESF10 at 40,44 and $48{ }^{\circ} \mathrm{C}$, however, detected at $58{ }^{\circ} \mathrm{C}$. In addition, ring-banded spherulites couldn't be detected for PESF20 in a wide temperature range $\left(28-44^{\circ} \mathrm{C}\right)$, that's to say, the incorporation of FDCA could restrict lamellar twisting and scrolling of PES segments.

\subsection{Mechanical properties}

Fig. 11 shows the stress-stain curves of PES, PEF, and PESFs. The Young's modulus $(E)$, strength $\left(\sigma_{\mathrm{m}}\right)$ and elongation at break $\left(\varepsilon_{\mathrm{b}}\right)$ are also summarized in Table 4 . As the crystallizability of PESF40-60 is weak and glass transition temperatures $\left(T_{\mathrm{g}}\right)$ are lower than the test temperature $\left(25^{\circ} \mathrm{C}\right)$, they are so soft that it is very difficult to molded. Tensile properties are not obtained for them.

The tensile strength of other PESFs ranges from 5 to $72 \mathrm{MPa}$, Young's modulus ranges from 30 to $2080 \mathrm{MPa}$, and elongation at break ranges from $3 \%$ to $1500 \%$. The tensile properties of PES $\left(E=110 \mathrm{MPa}, \sigma_{\mathrm{m}}=20 \mathrm{MPa}\right.$ and $\varepsilon_{\mathrm{b}}=510 \%$ ) are comparable to those of polyethylene (PE). Strain hardening phenomena appear for PES, PESF10, and PESF20 due to the strain-induced crystallization and chain alignment, which is also observed for other copolymers such as poly(butylene adipate-co-butylene furandicarboxylate) (PBAFs). ${ }^{23,33}$ Moreover, PES, PESF10 and PESF20 exhibit apparent yielding behaviors. At $\Phi_{\mathrm{EF}}$ from $0 \mathrm{~mol} \%$ to $20 \mathrm{~mol} \%$, the elongation apparently increases as the degree of crystallinity and the size of spherulites decrease as discussed above. However, the tensile strength of PESF10 and PESF20 are a little higher than that of PES, which may be caused by the relatively high molecular weight, indicating that mechanical properties commonly depend on many factors such as chain structure, molecular weight, crystallinity, spherulitic morphology, and $T_{\mathrm{g}}$. In contrast, at higher $\Phi_{\mathrm{EF}}(30 \mathrm{~mol} \%)$, the tensile strength of PESF30 is the lowest ( $5 \mathrm{MPa})$ due to the relatively low molecular weight and degree of crystallinity. At $\Phi_{\mathrm{EF}}$ from $80 \mathrm{~mol} \%$ to $100 \mathrm{~mol} \%$, a significant improvement in the Young's modulus and tensile strength is observed because the rigid structure increases with $\Phi_{\mathrm{EF}}$. Besides, in agreement with the literature, PEF displays brittle fracture behavior without yielding (elongation at break $=3 \%$ ), which is the major obstacle encountered in the applications. ${ }^{34}$ 


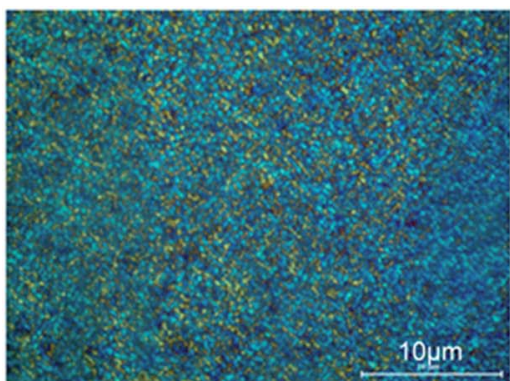

(al) $\mathrm{PES}$ at $58^{\circ} \mathrm{C}$



(bl) PESF10 at $40^{\circ} \mathrm{C}$

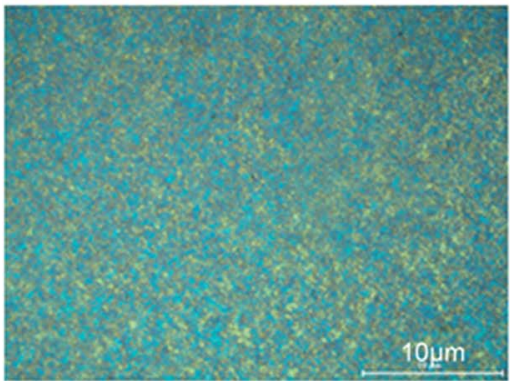

(cl) PESF20 at $28^{\circ} \mathrm{C}$

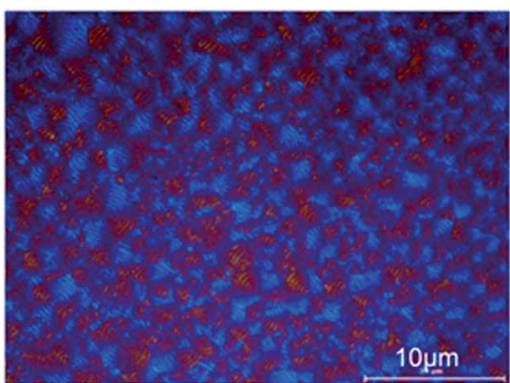

(a2) PES at $62^{\circ} \mathrm{C}$

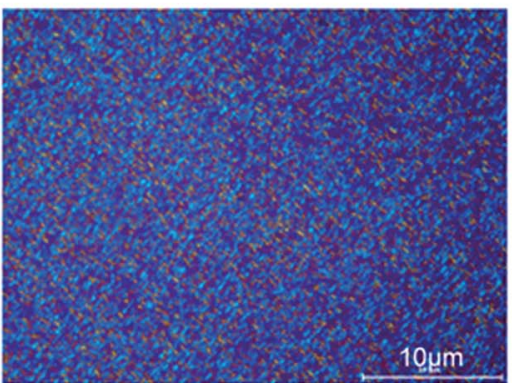

(b2) PESF10 at $44^{\circ} \mathrm{C}$

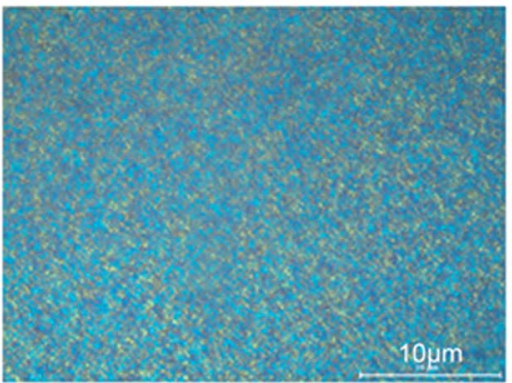

(c2) PESF20 at $32^{\circ} \mathrm{C}$

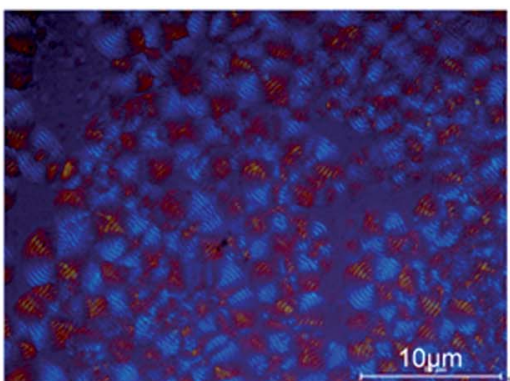

(a3) PES at $66^{\circ} \mathrm{C}$

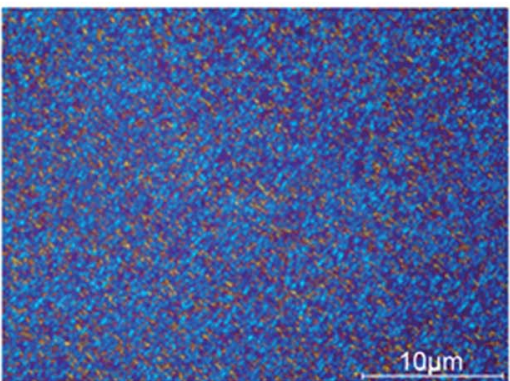

(b3) PESF10 at $48^{\circ} \mathrm{C}$

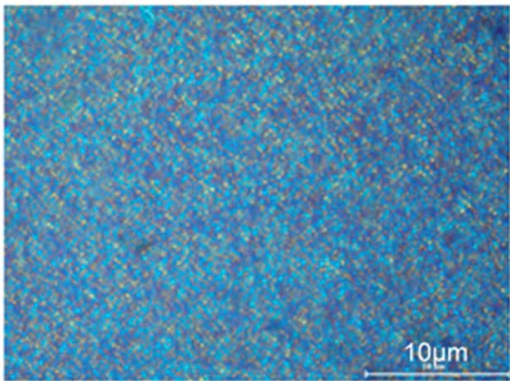

(c3) PESF20 at $36^{\circ} \mathrm{C}$

Fig. 10 Spherulitic morphologies of (a) PES, (b) PESF10, and (c) PESF20 after isothermal crystallization at indicated temperatures for 15 min.

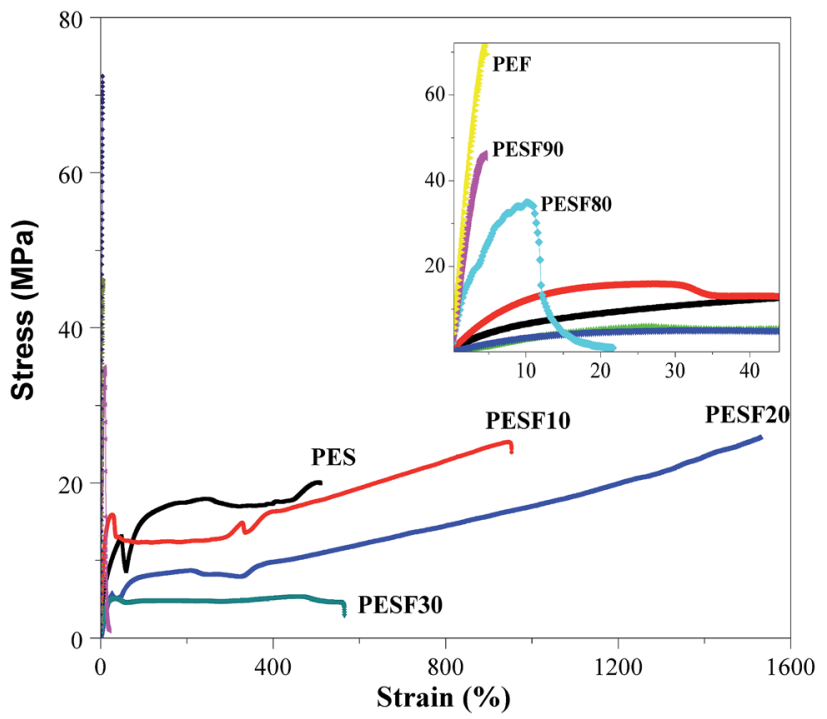

Fig. 11 Stress-strain curves of PES, PEF and PESFs.
Table 4 Young's modulus, tensile strength and elongation at break of PES, PEF, and PESFs

\begin{tabular}{lccc}
\hline Sample & $E(\mathrm{MPa})$ & $\sigma_{\mathrm{m}}(\mathrm{MPa})$ & \multicolumn{1}{c}{$\varepsilon_{\mathrm{b}}(\%)$} \\
\hline PES & $110 \pm 30$ & $20 \pm 2$ & $510 \pm 80$ \\
PESF10 & $170 \pm 50$ & $25 \pm 2$ & $950 \pm 150$ \\
PESF20 & $30 \pm 3$ & $26 \pm 3$ & $1500 \pm 190$ \\
PESF30 & $80 \pm 3$ & $5 \pm 1$ & $280 \pm 90$ \\
PESF80 & $940 \pm 50$ & $35 \pm 5$ & $12 \pm 3$ \\
PESF90 & $1160 \pm 400$ & $46 \pm 7$ & $4 \pm 3$ \\
PEF & $2080 \pm 100$ & $72 \pm 5$ & $3 \pm 1$ \\
& & & \\
\hline
\end{tabular}

In summary, compared with PES, EF-rich copolyesters have much higher Young's modulus and strength, while ES-rich copolyesters have much higher elongation at break. Results from the above data show that PESFs are the promising biobased copolymers and may have more interesting applications.

\section{Conclusions}

In this study, the novel biobased copolyesters poly(ethylene sebacate-co-ethylene 2,5-furandicarboxylate) (PESFs) derived 
from biobased sebacic acid (SA), ethylene glycol (EG), and 2,5furandicarboxylic acid (FDCA) were successfully prepared through a two-step melt polycondensation reaction. As confirmed by ${ }^{1} \mathrm{H}$ NMR, PESFs are random copolyesters. With increasing the content of FDCA unit, the glass transition temperatures of PESFs increase and they have excellent thermal stability. PESFs with lower contents in FDCA are able to crystallize from the melt. Compared with PES, PESF20 shows two melting peaks due to the formation of secondary crystals (small and imperfects crystals) caused by the incorporation of FDCA during the isothermal crystallization process. POM data show that the nucleation density of PESF10 and PESF20 increase and the size of spherulites decrease due to the chain irregularity caused by randomization distribution with the introduction of FDCA. However, WAXD data show that the crystal structure remains unchanged. Ring-banded spherulites couldn't be detected for PESF20 in a wide temperature range $\left(28-44{ }^{\circ} \mathrm{C}\right)$ as the incorporation of FDCA could restrict lamellar twisting and scrolling of PES segments. Compared with PES, EF-rich copolyesters have much higher Young's modulus and strength, while ES-rich copolyesters have much higher elongation at break. In summary, the thermal transition and mechanical properties are tunable with the composition.

\section{Acknowledgements}

Dr G. Q. Wang thanks the financial support by the Postdoctoral Science Foundation of Jilin Province, China (2015).

\section{Notes and references}

1 A. Gandini, Green Chem., 2011, 13, 1061-1083.

2 G. Z. Papageorgiou, V. Tsanaktsis and D. N. Bikiaris, Phys. Chem. Chem. Phys., 2014, 16, 7946-7958.

3 G. Z. Papageorgiou, V. Tsanaktsis, S. Exarhopoulos, D. G. Papageorgiou and D. N. Bikiaris, Polymer, 2014, 55, 3846-3858.

4 G. Z. Papageorgiou, V. Tsanaktsis, D. G. Papageorgiou, K. Chrissafis, S. Exarhopoulos and D. N. Bikiaris, Eur. Polym. J., 2015, 67, 383-396.

5 C. Lavilla, A. Alla, A. Martinez de llarduya, E. Benito, M. G. Garcia-Martin, J. A. Galbis and S. Munoz-Guerra, Biomacromolecules, 2011, 12, 2642-2652.

6 C. Japu, A. Martinez de Ilarduya, A. Alla, G. Mart, J. Galbis and S. Munoz-Guerra, Polym. Chem., 2014, 5, 3190-3202.

7 S. Thiyagarajan, W. Vogelzang, R. Knoop, A. Frissen, J. Haveren and D. Es, Green Chem., 2014, 16, 1957-1966.

8 E. Zakharova, A. Alla, A. Martinez de llarduya and S. Guerra, RSC Adv., 2015, 5, 46395-46404.
9 Z. Y. Wei, C. Zhou, Y. Yu and Y. Li, RSC Adv., 2015, 5, 4277742788.

10 H. D. Keith, Macromolecules, 1982, 15, 48-55.

11 F. W. Billmeyer, Macromolecules, 1969, 2, 103-105.

12 F. Koopman, N. Wierckx, J. Winde and H. Ruijssenaars, Bioresour. Technol., 2010, 101, 6291-6296.

13 A. Boisena, T. B. Christensena, W. Fub, Y. Y. Gorbanevc, T. S. Hansenc and J. S. Jensenb, Chem. Eng. Res. Des., 2009, 87, 1318-1327.

14 C. Moreaua, M. N. Belgacemb and A. Gandini, Top. Catal., 2004, 27, 11-30.

15 J. Lange, E. Heide, J. Buijtenen and R. Price, ChemSusChem, 2012, 5, 150-166.

16 A. Banerjee, G. Dick, T. Yoshino and M. Kanan, Nature, 2016, 531, 215-219.

17 S. Burgess, J. Leisen, B. Kraftschik, C. Mubarak, R. Kriegel and W. Koros, Macromolecules, 2014, 47, 1383-1391.

18 A. Gandini, A. J. D. Silvestre, C. P. Neto, A. F. Sousa and M. J. Gomes, J. Polym. Sci., Part A: Polym. Chem., 2009, 47, 295-298.

19 M. Gomes, A. Gandini, A. J. D. Silvestre and B. Reis, J. Polym. Sci., Part A: Polym. Chem., 2011, 49, 3759-3768.

20 M. Jiang, Q. Liu, Q. Zhang, C. Ye and G. Y. Zhou, J. Polym. Sci., Part A: Polym. Chem., 2012, 50, 1026-1036.

21 J. P. Ma, Y. Pang, M. Wang, J. Xu, H. Ma and X. Nie, J. Mater. Chem., 2012, 22, 3457-3461.

22 O. Grosshardt, U. Fehrenbacher, K. Kowollik, B. Tubke, N. Dingenouts and M. Wilhelm, Chem. Ing. Tech., 2009, 81, 1829-1835.

23 B. $\mathrm{Wu}, \mathrm{Y} . \mathrm{Xu}, \mathrm{Z} . \mathrm{Bu}, \mathrm{L} . \mathrm{Wu}, \mathrm{B} . \mathrm{Li}$ and P. Dubois, Polymer, 2014, 55, 3648-3655.

24 S. Mallakpour and M. Taghavi, Polym. J., 2009, 4, 308-318.

25 M. Avrami, J. Chem. Phys., 1941, 9, 177-184.

26 M. C. Tobin, J. Polym. Sci., Part B: Polym. Phys., 1976, 4, 22532257.

27 M. Avrami, J. Chem. Phys., 1941, 9, 177.

28 M. C. Tobin, J. Polym. Sci., Part B: Polym. Phys., 1976, 14, 2253.

29 C. Zhou, Z. Y. Wei, Y. Yu, Y. Wang and Y. Li, RSC Adv., 2015, 5, 68688-68699.

30 G. Stoclet, G. Sart, B. Yeniad, S. Vos and J. Lefebvre, Polymer, 2015, 72, 165-176.

31 X. F. Lu and J. N. Hay, Polymer, 2001, 42, 9423-9431.

$32 \mathrm{H}$. Wu and Z. Qiu, CrystEngComm, 2012, 14, 3586-3595.

33 W. Zhou, X. Wang, B. Yang, Y. Xu, W. Zhang, Y. Zhang and J. Ji, Polym. Degrad. Stab., 2013, 98, 2177-2183.

34 J. I. Knoop, W. Vogelzang and J. Haveren, J. Polym. Sci., Part A: Polym. Chem., 2013, 51, 4191-4199. 